Published in: Measurement, Volume 118, March 2018, Pages 372-378

Link to the printed version: https://www.sciencedirect.com/science/article/pii/S0263224117307650

\title{
Development of an efficient and thermally controlled Raman system for fast and safe molecular characterization of paint layers
}

\author{
Andrea Azelio Mencaglia, Iacopo Osticioli, Salvatore Siano* \\ Istituto di Fisica Applicata “N. Carrara”- Consiglio Nazionale delle Ricerche, Via Madonna del \\ Piano 10, 50019 Sesto Fiorentino, Italy. *) E-mail: S.Siano@ifac.cnrit
}

\begin{abstract}
An innovative high efficiency Raman system (exc. wav. $1064 \mathrm{~nm}$ ) for safe molecular characterisation of paint layers and other photosensitive materials has been developed and successfully tested. It was equipped with a novel optical probe, which has been designed and built in order to perform Raman scattering measurements on a relatively large spot at laser intensities lower than the typical ones of the commercial instruments. Original optical solutions were implemented in order to achieve such an improved efficiency. Furthermore, the instrument was also equipped with an active thermal control line allowing to prevent alterations of the material under study and to optimize the measurement cycles by means of suitable modulations of the laser power. Comparative tests using the novel analytical tool and an alternative setup based on a commercial Raman probe were carried out on a set of pure pigments and oil paint layers, which allowed assessing the significantly higher efficiency and reliability of the former with respect to the latter.
\end{abstract}

Keywords: Raman spectroscopy, pigment characterization, temperature control, painting, archaeometry.

\section{Introduction}

Along the last two decades, the application of Raman spectroscopy in archaeometry and conservation of cultural heritage, as well as in other fields, has undergone significant technological and applicative advances [1]. Nowadays, this vibrational technique is becoming the most used approach for the molecular identification of pigments, binders, ceramics, and other, as well as for recognizing alteration materials and performing technological studies of a variety of artefacts, in combination with other techniques within multidisciplinary approaches (see for example [2]). Furthermore, Raman spectroscopy has also been exploited for characterising the effectiveness of conservation treatments, such as those based on laser ablation [3]. This widespread use has been mainly favoured by the significant technological advances of the solid state lasers and optical components, along with the miniaturisation of the detectors, associated electronics, fiber coupled spectrometers, and personal computers. Such technological trends have allowed significant size and cost reductions of the analytical instruments and the development of portable devices $[4,5]$ with spectral resolution and signal to noise ratio not far from those of the laboratory instruments. This explains the increased number of works in the recent years using homemade portable Raman setups [6-9] with special-shape probes [10] or remotely operating [11, 12]. Recently, mobile instruments 
combining multiple spectroscopic techniques in the same system have been introduced [13-15] including for example also devices for planetary missions [16, 17].

Raman spectroscopy is usually referred to as a non-destructive technique although such a safe condition can be achieved only through careful optimisation of the irradiation parameters, or more often by operating at relatively low intensities. However, when the measurement time needs to be reduced in order to make practicable consecutive measurements of paint layers, organic fibers, plastics, and other, the achievement of non-destructive measurement conditions can be rather challenging because of the high photosensitivity and low critical thresholds of these materials. The excitation wavelength of $1064 \mathrm{~nm}$ is often preferable because of the strong fluorescence of organic materials at lower wavelengths (ex. $785 \mathrm{~nm}$ or lower). Anyway, because of the high intensities usually needed, the mentioned materials can easily undergo photothermal/chemical damage, such as discoloration, redox reactions, and material removal, with unacceptable visible alterations of the artefact under analysis. Furthermore, the operative conditions can become very critical whenever highly absorbing endogenous and/or exogenous materials are irradiated. Such an injury risk also represents a severe obstacle to the repeatability and reliability of the measurements and then to the possibility to implement automated compositional mapping and line-scanning Raman imaging.

In the present work, the development and comparative testing of an innovative portable Raman system (exc. wav. $1064 \mathrm{~nm}$ ) is reported. The instrument was equipped with an optical setup allowing operating with a relatively large laser spot along with automated energy release to the target driven by an online temperature monitoring. The basic idea, working principle, and technical details of the latter were recently reported $[18,19]$. Besides the improvement of the whole system, here, we focus on a set of specific technical solutions and on extensive comparison carried out on pigments and paint layers with an alternative setup using a commercial Raman probe. The results achieved show the significant advantages in terms of safety and efficiency the novel analytical system, in view of molecular mapping of paintings [20-22], polychrome stones, and other.

\section{Technology and methods}

The novel Raman system (system A in the following) including excitation source, probe, thermal control line, spectrometer, fibre coupling, and software was designed and built according to the following component concept design: laser source with analogic power control; reflective optics with a high numerical aperture for efficient collection of the scattered radiation; laser power feedback loop for preventing material alteration based on the continuous measurement of the temperature of the irradiated spot; precise focusing and visual monitoring using LED aiming beams and a USB endoscope camera; thermal stabilization of the IR spectrometer in order to reduce the fluctuation of the background; optimization of the optical coupling between the reflective collector and the spectrometer using a suitable fibre bundle; driver and applicative software allowing for full control of the operating conditions, data acquisition, management, and display.

In Fig. 1, a detailed schematic setup of the novel probe including the described components is displayed. As shown, the DP Nd:YAG (1064 nm, $500 \mathrm{~mW})$ laser was coupled to a hard clad silica (HCS) optical fiber (OF), 200/230 $\mu \mathrm{m}$ core/clad; the fiber output was imaged onto the sample (2.25× magnification) by means of an aspheric lens, $\mathrm{L}_{1}(\mathrm{f}=18.75 \mathrm{~mm})$. A $10 \mathrm{~nm}$ wide bandpass 
filter, BP, centered at $1064 \mathrm{~nm}$ was placed after the lens $\mathrm{L}_{1}$ in order to cut-off the Raman scattering contribution of the fiber. The optical collector was devised using a pair of off-axis, $90^{\circ}$, parabolic mirrors, $1 / 2$ inch diameter. The primary one, $\mathrm{M}_{1}$, which was drilled in order to let the laser beam pass through, had a focal length of $15 \mathrm{~mm}$ (NA: 0.41) while that of the secondary one, $\mathrm{M}_{2}$, was $25.4 \mathrm{~mm}$. The latter was selected in order to better match the numerical aperture of the fiber. The optimization of the coupling to the spectrometer was achieved through comparative tests using different fibers and bundles. The best results were provided by a fibre bundle with seven fibers $(\varnothing 105 / 125 \mu \mathrm{m}$ core/clad, NA = 0.22), packed circularly at the input tip (collector side) and linearly at the output one (spectrometer side), which was aligned along the direction of entrance slit. The notch filter $(\mathrm{N})$, centred @ 1064 nm, 44 nm-wide blocking window (OD > 6) for rejecting the elastic scattering component, was placed between the two mirrors. The IR spectrometer included a monochromator and a 512-pixel deep-cooled $\left(-55^{\circ} \mathrm{C}\right)$ InGaAs array detector (BaySpec Inc., CA, USA), allowing to cover the spectral range between $165-1825 \mathrm{~cm}^{-1}$ with a resolution of $8 \mathrm{~cm}^{-1}$. As anticipated above, the spectrometer was thermally stabilized using Peltier cells, suitable casing, fan, and heat sink components.

The thermopile sensor (TP) was calibrated according to a corrected blackbody emission formula and the direct measurement of the emissivity of the target in order to provide the temperature evolution $T(t)$ at the irradiated area, which was imaged on the sensor by means of the ZnSe lens, $\mathrm{L}_{2}$ (see [18] for further details). $T(t)$ was used as input observable of the power control, $P(t)$, with Proportional-Integral (PI) feedback:

$$
P(t)=\left\{\begin{array}{lll}
B \cdot \Delta T(t)^{\frac{1}{5}} \tanh \left(\frac{t}{\tau}\right)+C \cdot \int_{0}^{t} \Delta T\left(t^{\prime}\right)^{\frac{1}{5}} d t^{\prime}, & \text { if } \quad \Delta T(t)>0 \\
P_{\text {min }}, & \text { if } & \Delta T(t) \leq 0
\end{array}\right.
$$

where $\Delta T(t)=T_{\text {set }}-T(t), B, C$ and $\tau$ are adjustable parameters, $T_{\text {set }}$ is the expected temperature set by the operator, while $P_{\min }$ was set at $20 \mathrm{~mW}$ (arbitrary value selected in order to avoid the switchoff of the laser when deep power modulations were induced by rapid temperature rises).

The suitable selection of the $B, C$ and $\tau$ parameters allowed optimizing the laser energy release to the target in order to avoid undesired overheating and alteration of the sample under analysis. In some details $\tau=0.7 \mathrm{~s}$ guaranteed a gradual power increase during the onset phase, which was needed in order to avoid too high thermal gradients within the response time of the thermopile, TP $(1.3 \mathrm{~s}) . B$ can assume values ranging between 2.8 and $28 \mathrm{~mW}^{\circ} \mathrm{C}^{-1 / 5}$, while $\mathrm{C}$ ranges between $8.4 \cdot 10^{-3}$ and $42 \cdot 10^{-3} \mathrm{~mW}^{\circ} \mathrm{C}^{-1 / 5} \mathrm{~s}^{-1}$.

Three light beams (less than $1 \mathrm{~mm}$ diameter) were projected onto the sample surface by three LEDs (red, blue and green: R, G, B in Fig. 1), coupled to steel hollow needles $25 \mathrm{~mm}$ length, in such a way they overlapped at the focal spot of the system. These aiming beams along with an USB endoscope camera (E in Fig. 1) allowed controlling easily the correct positioning of the sample before the spectrum collection.

The performances of the Raman system A, just described, were compared with those of an alternative setup (system B) built using the same laser excitation source and spectrometer as those of the system A and the commercial probe schematized in Fig. 2. In this second case, the scattered 
light was collected and collimated by the same lens, $\mathrm{L}_{2}(\mathrm{NA}=0.4)$, used for focusing the laser beam (focal spot diameter of $105 \mu \mathrm{m}$ ). It was then extracted from the incidence optical axis by means of a dichroic mirror $(\mathrm{DM})$, bent using a flat mirror $(\mathrm{M})$, filtered $(\mathrm{N})$, coupled to the optical fibre $(200 \mu \mathrm{m}$ core diameter), and eventually sent to the spectrometer.

The comparison between the two systems was carried out by considering the following exposure-normalised detection efficiency parameter:

$$
\mathcal{E}=\frac{I_{R}}{\int_{0}^{t_{L}} I_{L}(t) d t}=\frac{I_{R}}{F_{t o t}}=\left[\frac{\text { counts }}{J / \mathrm{cm}^{2}}\right],
$$

where $I_{R}$ is the peak intensity of the Raman band (after baseline subtraction) selected for comparison, $I_{L}$ the laser intensity, $t_{L}$ the irradiation time, and $F_{\text {tot }}$ the total fluence of radiant exposure at the focal laser spot. Alternatively, the detection performance can be compared by considering the counts/sec at fixed laser intensity.

\subsection{Characterization of system $A$}

System A was preliminarily characterized in terms of maximum laser power release to the target, spot size and distribution. Afterwards, the correct confocal alignment of the excitation beam and signal beam, as defined by the collection optics was carried out. The two beams define a working range (volume) where the surface of the sample should be located in order to allow effective Raman detection. In addition, the correct alignment of the thermal detection group ( $\mathrm{TP}$ and $\mathrm{L}_{2}$ ) was also geometrically quantified.

The laser power distribution within the focal spot was measured by means of a beam analyzer (LBA 500PC, Spiricon Inc., UT, USA): it resulted to be $450 \mu \mathrm{m}$ in diameter and exhibited excellent top-hat distribution, as displayed in Fig. 3a. The maximum power release to the target was $360 \mathrm{~mW}$ and the corresponding maximum intensity was $226 \mathrm{~W} / \mathrm{cm}^{2}$.

The beam analyzer was also used in order to correctly align and focus the collection optical group. To this goal, the spot of the incident laser beam was overlapped at the focus with that of the beam achieved by illuminating the fiber bundle from the spectrometer side. As shown in Figs. 3, the two spots, obtained using a $7 \times 105 / 125 \mu \mathrm{m}$ (Fig 3b) and a 7×200/230 $\mu \mathrm{m}$ (Fig 3c) fiber bundles, respectively, were in satisfactory matching with the laser spot (white circle). In particular, the spot of the smaller bundle exhibited a better size matching with that of the laser.

The assessment of the alignment of the thermal sensor was achieved by scanning a thin metallic wire across the laser spot area, in two directions $(\mathrm{X}, \mathrm{Y})$ perpendicular to the axis of the laser beam. The wire was heated at a constant temperature with electric current and for each measuring point of the scans, two temperatures were acquired: with the laser switched OFF and ON, respectively. When the wire was located in the laser spot area, a temperature rise was detected, due to the laser heating. As shown in Fig. 4, the X and Y scan with the laser OFF defined the cross sectional area of the focal region from where the TP sensor was able to receive the thermal signal (blue and green lines, respectively). Similar scans with the laser ON (yellow and red lines, respectively) and the corresponding heating was measured. Figure 4 shows that a very good alignment was achieved since a coincident peak position was detected, and that the thermal line detection area was a bit larger than the laser spot area (about 1.5-2 time larger). Therefore, it should be considered that the temperature measured could be, in some extent, underestimated, especially in the cases of short 
time exposures and samples presenting low thermal diffusivity.

The larger width of the peaks in the $\mathrm{Y}$ direction is due to the geometrical factor $1 / \cos (\theta)$, being $\theta$ the angle between the thermal line optical axis and the laser beam axes $\left(40^{\circ}\right)$.

In order to characterize the system in terms of depth of focus, cinnabar powder was used as test sample, which was placed at different distances around the optimum position along the laser beam axis (assumed to be $\mathrm{Z}=0$ ). At each position a spectrum was collected, the temperature after $7 \mathrm{~s}$ from the beginning of the laser radiation was measured using the thermal sensor, and a picture of the scene as seen by the endoscope was taken. The results of this test are summarized in the plot of Fig. 5 reporting the intensity of the band of cinnabar at $252 \mathrm{~cm}^{-1}$ (solid blue line), and its difference with respect to the intensity of the band at $309 \mathrm{~cm}^{-1}$ (dashed green line), and the mentioned temperature (red line). Position shifts of $\pm 0.5 \mathrm{~mm}$ around $\mathrm{Z}=0$ returned Raman signals within $90 \%$ of the maximum. The coincidence of the maximum temperature at $\mathrm{Z}=0$ confirmed the good alignment of the thermal line. Finally, the inset pictures of Fig. 5 taken at the various position show how the best overlap the RGB aiming beams (better shown on white target at the top right corner of the plot) also occurs at $\mathrm{Z}=0$ thus confirming the effectiveness such a focusing approach for polychrome samples based on multicolor LED beams.

\section{Characterization of system $B$}

The system B was characterized in a similar way as the system A in terms of spot size and distribution and laser intensity at the target. The maximum value of the latter resulted to be 4.16 $\mathrm{kW} / \mathrm{cm}^{2}$, as calculated considering the measured power of $360 \mathrm{~mW}$ and laser spot diameter of 105 $\mu \mathrm{m}$. The latter corresponded to the fiber core diameter and was determined by means of the mentioned beam analyzed (Fig 3d). It must be observed that in the present case the intensity distribution was rather peaked at the center and hence decidedly less homogeneous than that of the system A (Fig. 3a).

Extensive measurement tests have been carried out on a set of mercury, iron, copper, lead and cadmium based pigment samples using both the Raman systems described above. These were carried out after determining the discoloration thresholds of the various pigments through gradual exposure increases and microscope examinations, in order to define safe operative irradiation ranges. The comparison pointed out the detection efficiency of the system A was significantly higher than that of the system B. Thus for example, as shown in Fig. 6, reporting the spectra of cinnabar $(\mathrm{HgS})$, a similar maximum of the most intense band at $252 \mathrm{~cm}^{-1}$ was achieved with the system A using much lower intensity and radiant exposure than those needed for the system B (100 $\mathrm{J} / \mathrm{cm}^{2}$ against $1.2 \mathrm{~kJ} / \mathrm{cm}^{2}$ ). The corresponding efficiency parameters (Eq. 2) were: $\varepsilon_{A}=186$ counts $\cdot \mathrm{cm}^{2} / \mathrm{J}, \varepsilon_{B}=12$ counts $\cdot \mathrm{cm}^{2} / \mathrm{J}$. For both spectra the acquisition time was $t_{L A}=t_{L B}=3 \mathrm{~s}$.

The signal improvement achieved has to be attributed to the following main features of the novel system (A): 1) larger laser spot (450 against $105 \mu \mathrm{m}$ ) with a top-hat energy distribution produced by the single lens ( $L_{l}$ in Fig. 1) imaging configuration; 2) high numerical aperture optical collection; improved coupling to the spectrometer using the fiber bundle FB (Fig. 1) with the mentioned 
asymmetric packing, which allowed collecting more scattered light from the irradiated spot and better exploit the active area of the sensor array of the spectrometer.

In all the cases, the acquisition time can be reduced by increasing the excitation intensity, according to the linear dependence of the Raman scattering on the latter within a given intensity range. However, the irradiation parameters should be kept well below the alteration threshold of the material under study.

As mentioned above, the present configuration of the system A allowed a maximum intensity release to the target of about $226 \mathrm{~W} / \mathrm{cm}^{2}$. The permanent darkening of cinnabar was observed after about $3 \mathrm{~s}$ at $100 \mathrm{~W} / \mathrm{cm}^{2}$, which corresponded to a peak temperature of $180^{\circ} \mathrm{C}$, as measured through the thermal monitor line. Conversely, alteration of cinnabar using the system B was observed after a similar irradiation time at $600 \mathrm{~W} / \mathrm{cm}^{2}$. Such a significant difference between the two alteration thresholds has to be attributed to the different spot diameters and beam distributions of the two systems.

In order to safely expose the sample, the system A allowed to activate the PI feedback control loop according to Eq. (1). It was then possible to start the spectrum detection either soon after the laser was switched $\mathrm{ON}$ or, alternatively, when the surface temperature of the target approached the $T_{\text {set }}$ value within a certain $\Delta T$. Thus for example in Fig. 7a, several spectra of cinnabar are shown, which were collected using $3 \mathrm{~s}$ integration time, by starting the acquisition only when the target temperature was close to $T_{\text {set }}\left(\Delta T=T-T_{\text {set }}=-2^{\circ} \mathrm{C}\right)$. The respective temperature temporal profiles are displayed in Fig. 7b, where the last $3 \mathrm{~s}$, during which the spectra have been collected, are highlighted with a double colour stretch of the curves.

These results provide evidence, the system A offers the possibility to significantly reduce the acquisition time and prevent undesired alterations of the sample. In particular, Fig. 7a shows that non-destructive spectral analysis of cinnabar was carried out up to a surface temperature set around $150{ }^{\circ} \mathrm{C}$, which corresponds to the maximal practicable acquisition speed on this pigment (i.e. detection time down to a fraction of second allow achieving up to several thousand counts).

Similar tests were carried out on azurite (Fig. 8), $\mathrm{Cu}_{3}\left(\mathrm{CO}_{3}\right)_{2}(\mathrm{OH})_{2}$, which exhibited a permanent darkening at a laser intensity of about $120 \mathrm{~W} / \mathrm{cm}^{2}$, slightly higher than that of cinnabar. Also in this case the efficiency (which was in general lower than for cinnabar) of the system A was significantly higher than that of the system B. This was calculated in different irradiation conditions and showed a pronounced dependence on the radiant exposure: $\varepsilon_{A}=0.22-1.28$ for radiant exposures between 1-6 $\mathrm{kJ} / \mathrm{cm}^{2}$ and the maximum efficiency was achieved at $2 \mathrm{~kJ} / \mathrm{cm}^{2}$. Such a behaviour of $\varepsilon_{A}$, which was observed also for cinnabar, could likely be related to the possible reversible variation of the optical parameters of the pigment under irradiation at increasing laser intensities and total radiant exposure. In view of future substantial systematic insights on this feature, where both the dependences on total fluence and intensity must be investigated, let also observe that the intensities of the main band of cinnabar at $252 \mathrm{~cm}^{-1}$ exhibited a different behaviour with respect to that at $345 \mathrm{~cm}^{-1}$. As shown in Fig. 9, both of them showed saturating increase with the radiant exposure but the respective efficiency rises and maximal values were very different (above 200 and 80 counts $\mathrm{cm}^{2} / \mathrm{J}$, respectively).

Spectral analyses carried out on hematite pure pigment and red ochre linseed oil paint layer on gypsum and rabbit glue preparation of a wooden panel are reported in Fig. 10. As shown, intermediate efficiencies between those of cinnabar and azurite were found and the system A 
confirmed its superior performance. The best exposure-normalized efficiency $\left(\varepsilon_{A}=2.32\right.$ counts. $\mathrm{cm}^{2} / \mathrm{J}$, as calculated by considering the band at about $290 \mathrm{~cm}^{-1}$ ) was found at $350 \mathrm{~J} / \mathrm{cm}^{2}$ (orange spectrum), whereas a saturation effect was observed at about $1 \mathrm{~kJ} / \mathrm{cm}^{2}$. Of course, there is not a reciprocity relationship between efficiency and exposure because of the combined dependence on the laser intensity (compare yellow, $30 \mathrm{sec}$ at $35 \mathrm{~W} / \mathrm{cm}^{2}$ and violet, $10 \mathrm{sec}$ at $105 \mathrm{~W} / \mathrm{cm}^{2}$ : same total exposure, different efficiencies). The main bands of red ochre and underlying gypsum preparation were clearly recognizable in the spectrum at $350 \mathrm{~J} / \mathrm{cm}^{2}$, which was collected in $10 \mathrm{~s}$ using a laser intensity of about $35 \mathrm{~W} / \mathrm{cm}^{2}$. The observed intensities of the Raman bands suggest that a slightly higher intensity and shorter acquisition time (ex. $5 \mathrm{~s}$ ) could be used in scanning operative conditions, where a suitable trade-off between full prevention of any material alteration and measurement speed must be determined.

Further confirmations of the higher efficiency and reliability offered by the system A were achieved through additional characterization tests carried out on minium $\left(\mathrm{Pb}_{3} \mathrm{O}_{4}\right.$, red $)$ and cadmium yellow $(\mathrm{CdS})$ in linseed oil. The spectra collected using the present two Raman systems at the same radiant exposure are displayed in Fig. 11. As shown, similar band intensities were achieve with very different radiant exposures, being those of the system A between 18-19 times lower than those of the system B.

\section{Conclusions}

An innovative Raman system implementing a novel probe and equipped with a thermal control line for investigating the temperature dependence and preventing undesired alterations of the material under analysis has been developed. The comparison of its performances with those of an alternative system including a commercial Raman probe evidenced the significant advantages of the novel instrument. This was also equipped with an endoscope camera and three aiming LED beams for easy, precise, and repeatable focusing of the laser and collecting optical group.

The tests were carried out on pure pigments and paint layers and the comparison of the instrumental performances was achieved using an exposure-normalised efficiency parameter. This allowed demonstrating the significant signal improvement provided by the novel system, which can operate at intensities, radiant exposures and material temperatures much lower than the usual ones or it can significantly reduce the spectrum acquisition time. Such features are very promising in order to develop an efficient Raman scanner able to provide automated molecular mapping of valuable paintings and, more in general, of polychrome surfaces, without relevant risks of material alterations.

Further technical improvements, comparisons of the performances, extensive application tests on further paint layers, and the determination of the respective optimized operative conditions will be carried out in the next future. Furthermore, the Raman system described in this work will assembled on a five-axis Raman scanner, which is currently under construction.

\section{Acknowledgements}

The present work represents the first step towards the development of a Raman scanner foreseen in the project FOTONART funded by the Fondazione CR Firenze, while the development of the 
thermal control line for preventing material alteration was carried out within the activities of the European project IPERION-CH "Integrated Platform for the European Research Infrastructure on Cultural Heritage” (H2020-INFRAIA-2014-2015, Grant Agreement n. 654028).

\section{References}

[1] D. Bersani, C. Conti, P. Matousek, F. Pozzi, P. Vandenabeele, Methodological evolutions of Raman spectroscopy in art and archaeology, Anal. Methods. 8 (2016) 8395-8409. DOI: 10.1039/c6ay02327d.

[2] C. Germinario, G. Cultrone, A. De Bonisc, F. Izzo, A. Langella, M. Mercurio, V. Morrac, A. Santoriello, S. Siano, C. Grifa, The combined use of spectroscopic techniques for the characterisation of Late Roman common wares from Benevento (Italy), Measurement (in press). DOI: 10.1016/j.measurement.2016.08.005

[3] S. Siano, J. Agresti, I. Cacciari, D. Ciofini, M. Mascalchi, I. Osticioli, A.A. Mencaglia, Laser cleaning in conservation of stone, metal, and painted artifacts: state of the art and new insights on the use of the Nd:YAG lasers, Appl. Phys. A. 106 (2011) 419-446. DOI:10.1007/s00339-011-66908 .

[4] P. Colomban, The on-site/remote Raman analysis with mobile instruments: A review of drawbacks and success in cultural heritage studies and other associated fields, J. Raman Spectrosc. 43 (2012) 1529-1535. DOI: 10.1002/jrs.4042.

[5] P. Vandenabeele, H.G.M. Edwards, J. Jehlička, The role of mobile instrumentation in novel applications of Raman spectroscopy: archaeometry, geosciences, and forensics, Chem. Soc. Rev. 43 (2014) 2628-49. DOI: 10.1039/c3cs60263j.

[6] P. Vandenabeele, T.L. Weis, E.R. Grant, L.J. Moens, A new instrument adapted to in situ Raman analysis of objects of art, Anal. Bioanal. Chem. 379 (2004) 137-142. DOI: 10.1007/s00216-0042551-z.

[7] A. Deneckere, M. Leeflang, M. Bloem, C.A. Chavannes-Mazel, B. Vekemans, The use of mobile Raman spectroscopy to compare three full-page miniatures from the breviary of Arnold of Egmond, Spectrochim. Acta Part A: Mol. Biomol. Spectrosc. 83 (2011) 194-199. DOI: 10.1016/j.saa.2011.08.016.

[8] P. Vandenabeele, J. Tate, L. Moens, Non-destructive analysis of museum objects by fibre-optic Raman spectroscopy, Anal. Bioanal. Chem. (2007) 813-819. DOI: 10.1007/s00216-006-0758-x.

[9] J.T. Motz, M. Hunter, L.H. Galindo, J.A. Gardecki, J.R. Kramer, R.R. Dasari, M.S. Feld, Optical Fiber Probe for Biomedical Raman Spectroscopy, Appl. Opt. 43 (2004) 542. DOI: 10.1364/AO.43.000542.

[10] P.D. Pudney, E.Y.M. Bonnist, P.J. Caspers, J.-P. Gorce, C. Marriot, G.J. Puppels, S. Singleton, M. J. G. van der Wolf, A new in vivo Raman probe for enhanced applicability to the body, Appl. Spectrosc. 66 (2012) 882-91. DOI: 10.1366/12-06640.

[11] A. Brambilla, I. Osticioli, A. Nevin, D. Comelli, C. D’Andrea, C. Lofrumento, G. Valentini, R. Cubeddu, A remote scanning Raman spectrometer for in situ measurements of works of art., Rev. Sci. Instrum. 82 (2011) 63109. DOI: 10.1063/1.3600565.

[12] B. Zachhuber, C. Gasser, G. Ramer, E.T.H. Chrysostom, B. Lendl, Depth profiling for the identification of unknown substances and concealed content at remote distances using time-resolved stand-off Raman spectroscopy, Appl. Spectrosc. 66 (2012) 875-881. DOI: 10.1366/12-06602. 
[13] S. Dochow, D. Ma, I. Latka, T. Bocklitz, B. Hartl, J. Bec, H. Fatakdawala, E. Marple, K. Urmey, S. Wachsmann-Hogiu, M. Schmitt, L. Marcu, J. Popp, Combined fiber probe for fluorescence lifetime and Raman spectroscopy, Anal. Bioanal. Chem. (2015) 8291-8301. DOI: 10.1007/s00216-015-8800-5.

[14] I. Osticioli, N.F.C. Mendes, Nevin, Zoppi, C. Lofrumento, M. Becucci, E. M. Castellucci, A new compact instrument for Raman, laser-induced breakdown, and laser-induced fluorescence spectroscopy of works of art and their constituent materials., Rev. Sci. Instrum. 80 (2009) 76109. DOI: 10.1063/1.3184102.

[15] A. Giakoumaki, I. Osticioli, D. Anglos, Spectroscopic analysis using a hybrid LIBS-Raman system, Appl. Phys. A Mater. Sci. Process. 83 (2006). DOI: 10.1007/s00339-006-3541-0.

[16] S.K. Sharma, A.K. Misra, P.G. Lucey, R.C.F. Lentz, A combined remote Raman and LIBS instrument for characterizing minerals with $532 \mathrm{~nm}$ laser excitation, Spectrochim. Acta Part A: Mol. Biomol. Spectrosc.73 (2009) 468-476. DOI: 10.1016/j.saa.2008.08.005.

[17] A. Ellery, D. Wynn-Williams, J. Parnell, H.G.M. Edwards, D. Dickensheets, The role of Raman spectroscopy as an astrobiological tool in the exploration of Mars, J. Raman Spectrosc. 35 (2004) 441-457. DOI: 10.1002/jrs.1189.

[18] A.A. Mencaglia, I. Osticioli, S. Siano, Optimising Raman spectroscopy for characterising biological growths on stone artefacts, in: IET Conf. Publ., 2015. DOI: 10.1049/cp.2015.0188.

[19] I. Osticioli, A.A. Mencaglia, S. Siano, Temperature-controlled portable Raman spectroscopy of photothermally sensitive pigments, Sensors Actuators B Chem. 238 (2017) 772-778. DOI: 10.1016/j.snb.2016.07.104.

[20] P. Ropret, C. Miliani, S.A. Centeno, F. Rosi, Advances in Raman mapping of works of art, Tavzes a , b, (2010). DOI: 10.1002/jrs.2733.

[21] S. Mosca, R. Alberti, T. Frizzi, A. Nevin, G. Valentini, D. Comelli, A whole spectroscopic mapping approach for studying the spatial distribution of pigments in paintings, Appl. Phys. A Mater. Sci. Process. 122 (2016) 1-10. DOI: 10.1007/s00339-016-0345-8.

[22] D. Lauwers, P. Brondeel, L. Moens, P. Vandenabeele, In situ Raman mapping of art objects, Philos. Trans. A. accepted (2016). DOI: 10.1098/rsta.2016.0039. 


\section{Figure captions}

Fig. 1 Schematic set up of the novel probe implemented in the Raman system A. $\mathrm{L}_{1-2}$ : lenses. $\mathrm{M}_{1-2}$ : $90^{\circ}$ off-axis parabolic mirrors. BP and $\mathrm{N}$ : bandpass and notch filter, respectively. TP: thermopile. R, G, B: red green and blue LEDs, respectively. E: endoscope camera.

Fig. 2 Schematic setup of the commercial probe used in the Raman system B. $\mathrm{L}_{1-3}$ : lenses. DM and $\mathrm{M}$ : dichroic mirror and flat mirror, respectively. BP and N: band pass and notch filter, respectively.

Fig. 3 Beam profiles of the focal laser spots of the system A (a) and B (d), respectively, along with those of the illuminated entrance of the $7 \times 105 / 125 \mu \mathrm{m}$ fiber bundle (b), and $7 \times 200 / 230 \mu \mathrm{m}$ fiber bundle (c), respectively.

Fig. 4 Temperature spatial profiles as detected by the thermopile sensor during $\mathrm{X}$ and $\mathrm{Y}$ orthogonal scans of a hot wire in the focal plane with laser OFF and ON, respectively.

Fig. 5 Assessment of the depth of focus of the system A by plotting the spatial dependence of the relative height of the two main Raman bands of cinnabar powder, of their difference, and of the corresponding temperature profile, as measured by the thermal sensor. Inset pictures show the position of the spots produced at the target surface by the RGB LED aiming beams.

Fig. 6 Raman spectra of cinnabar as collected by means of the system A (red line) and the system B (blue line), respectively, using very different irradiation parameters.

Fig. 7 Raman spectra of cinnabar (a) achieved at almost constant temperatures with the PI feedback control loop activated and corresponding $\mathrm{T}(\mathrm{t})$ profiles $(\mathrm{b})$ for several values of $\mathrm{T}_{\text {set }}$. The spectra (a) were achieved during the last $3 \mathrm{~s}$ of each profile temperature, with the exposure values reported in legend. The drastic increase of the continuum observed at 180 ${ }^{\circ} \mathrm{C}$ (a) highlights the occurrence of the permanent alteration of the sample.

Fig. 8 Spectra of azurite provided by the systems A and B at different radiant exposure $(60 \mathrm{~s}$ integration time). The legend also report the respective efficiencies as evaluated for the peak at $1100 \mathrm{~cm}^{-1}$ are reported.

Fig. 9 Detection efficiency of the system A for the cinnabar bands at 252 and $345 \mathrm{~cm}^{-1}$ vs radiant exposure. The black square at $280 \mathrm{~J} / \mathrm{cm}^{2}$ indicate the saturation of the counts of the band at $252 \mathrm{~cm}^{-1}$ saturated.

Fig. 10 Spectra of hematite pure pigment (two dotted spectra at the bottom) and of red ochre paint layer (three solid spectra), as measured using the systems A and B, respectively, and different irradiation parameters. The detection efficiency, $\varepsilon$, refers to the band at $290 \mathrm{~cm}^{-1}$.

Fig. 11 Raman spectra at different radiant exposures of minium (a) and cadmium yellow (b) oil paint, as measured using the system A and B, respectively, showing the higher efficiency of the former. 


\section{Highlights}

1) A very efficient and safe portable Raman system was developed.

2) High efficiency relies on a set of optical solutions which improve the signal.

3) Side effects are prevented by power control driven by active thermal monitoring.

4) The problem of rapid Raman characterisation of photosensitive paint layers was solved. 
Fig. 1 Schematic set up of the novel probe implemented in the Ra

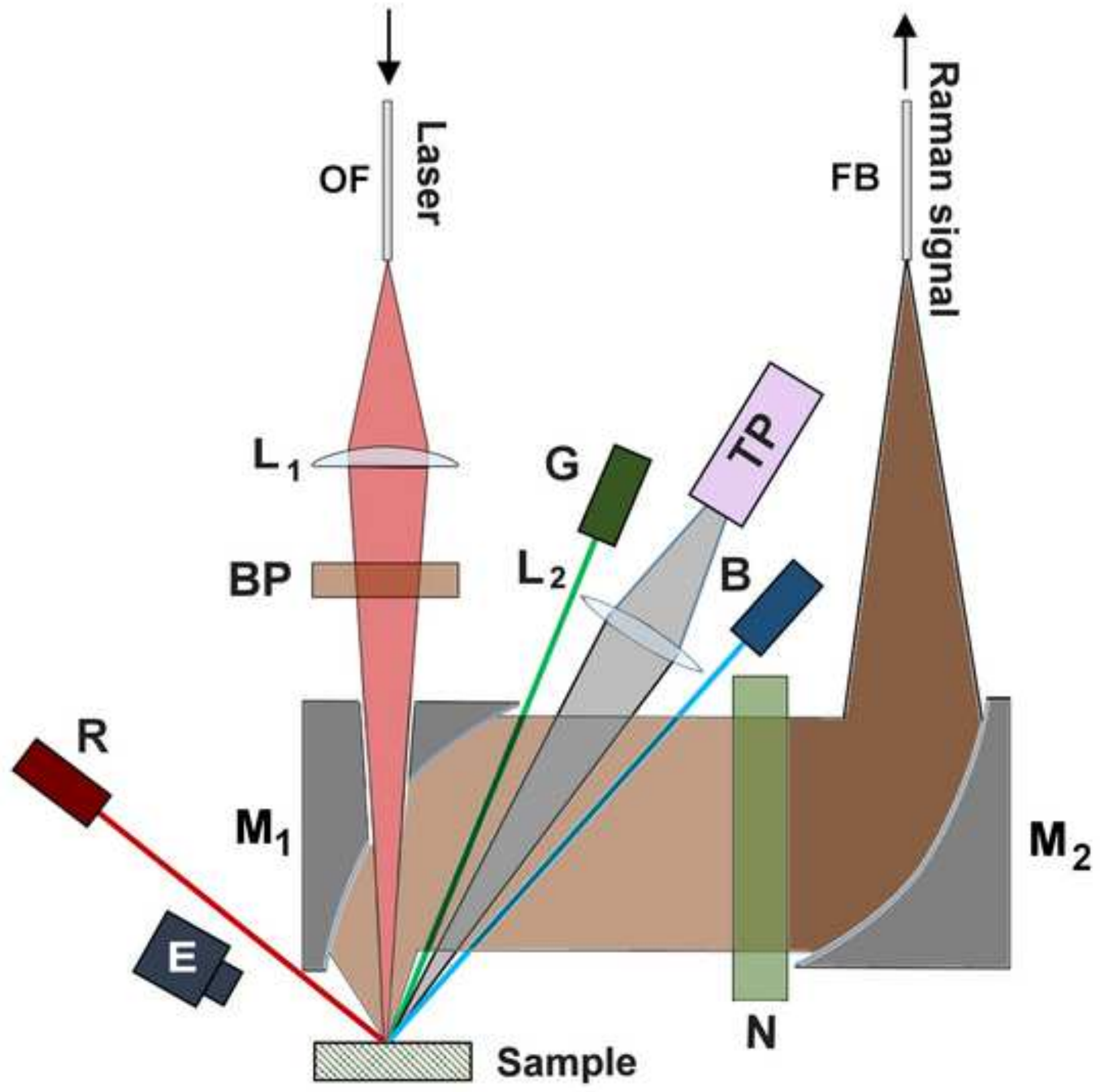


Fig. 2 Schematic setup of the commercia

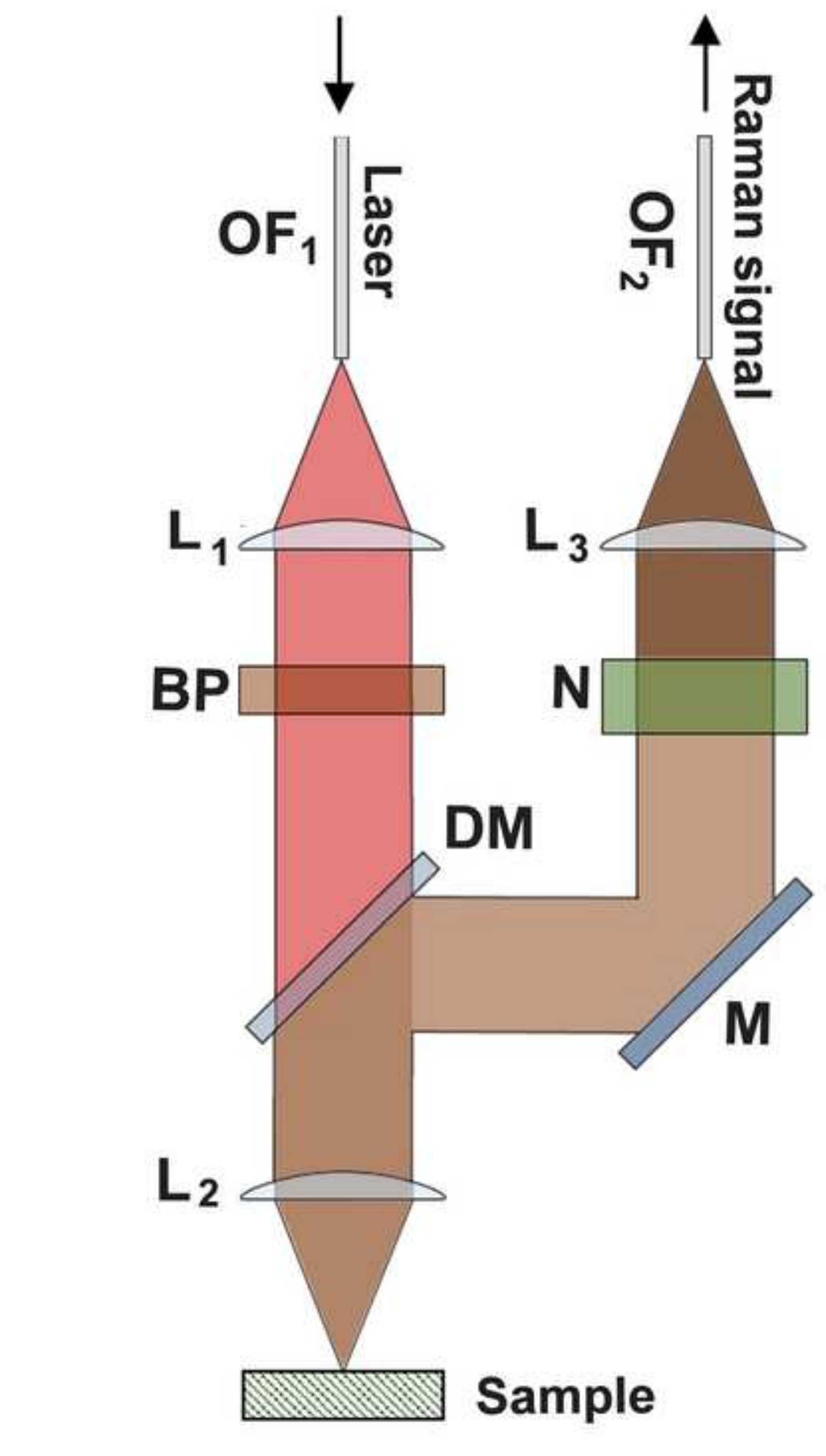

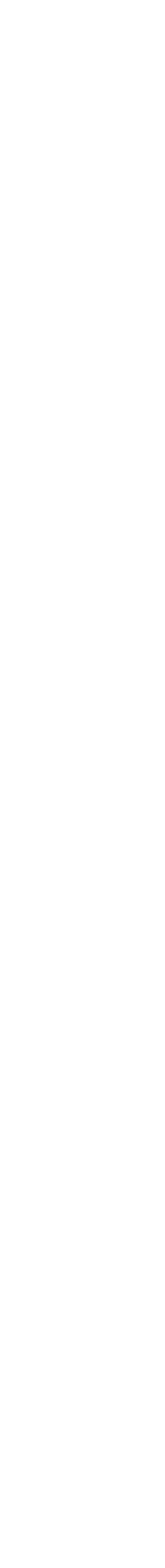

(1)
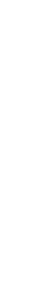

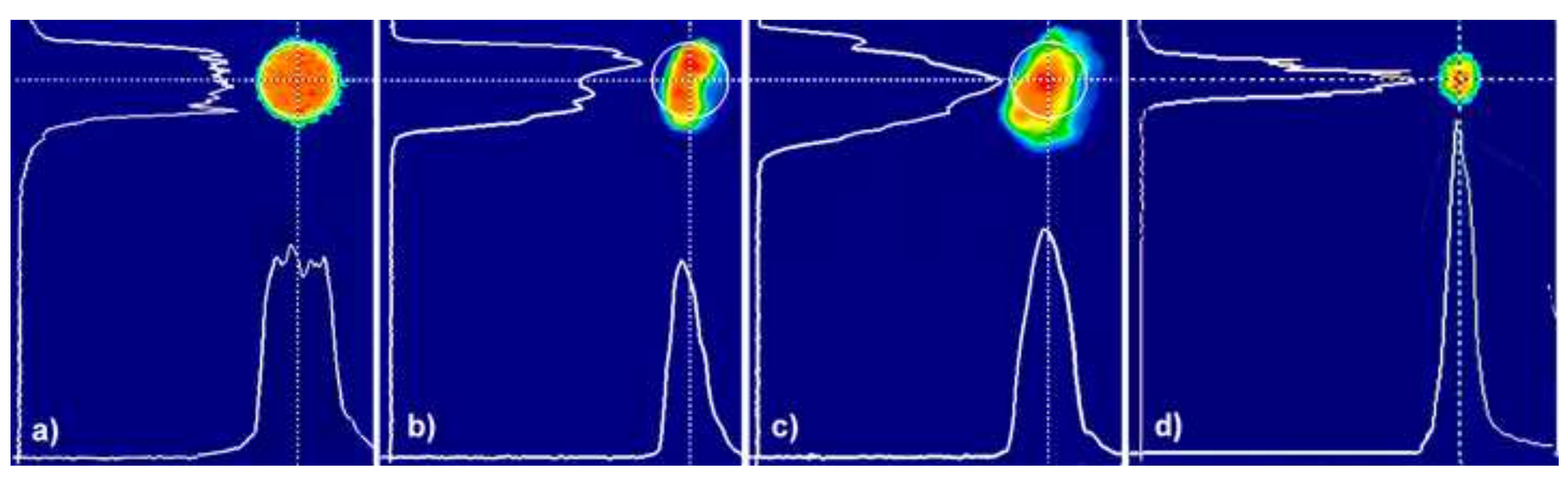


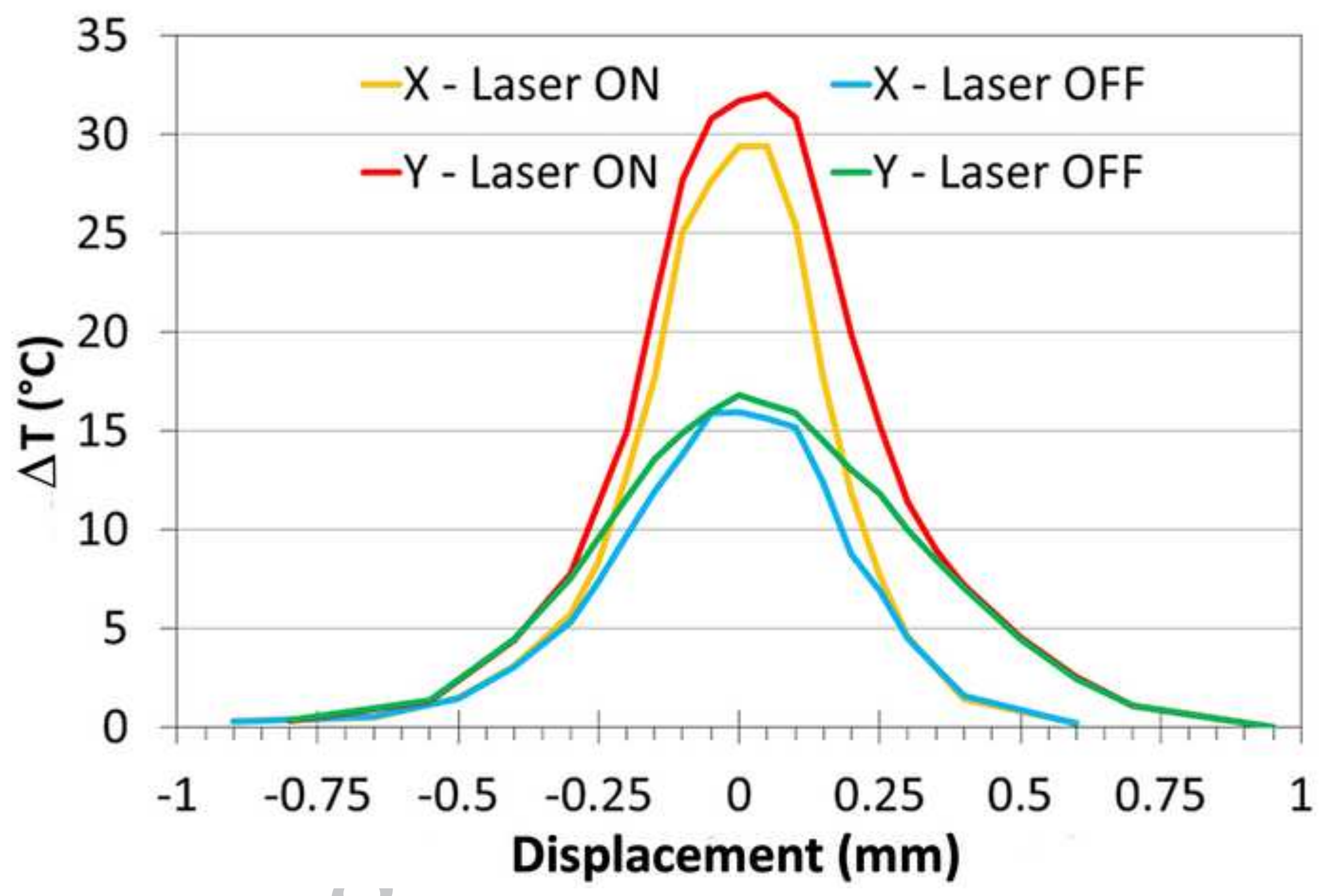




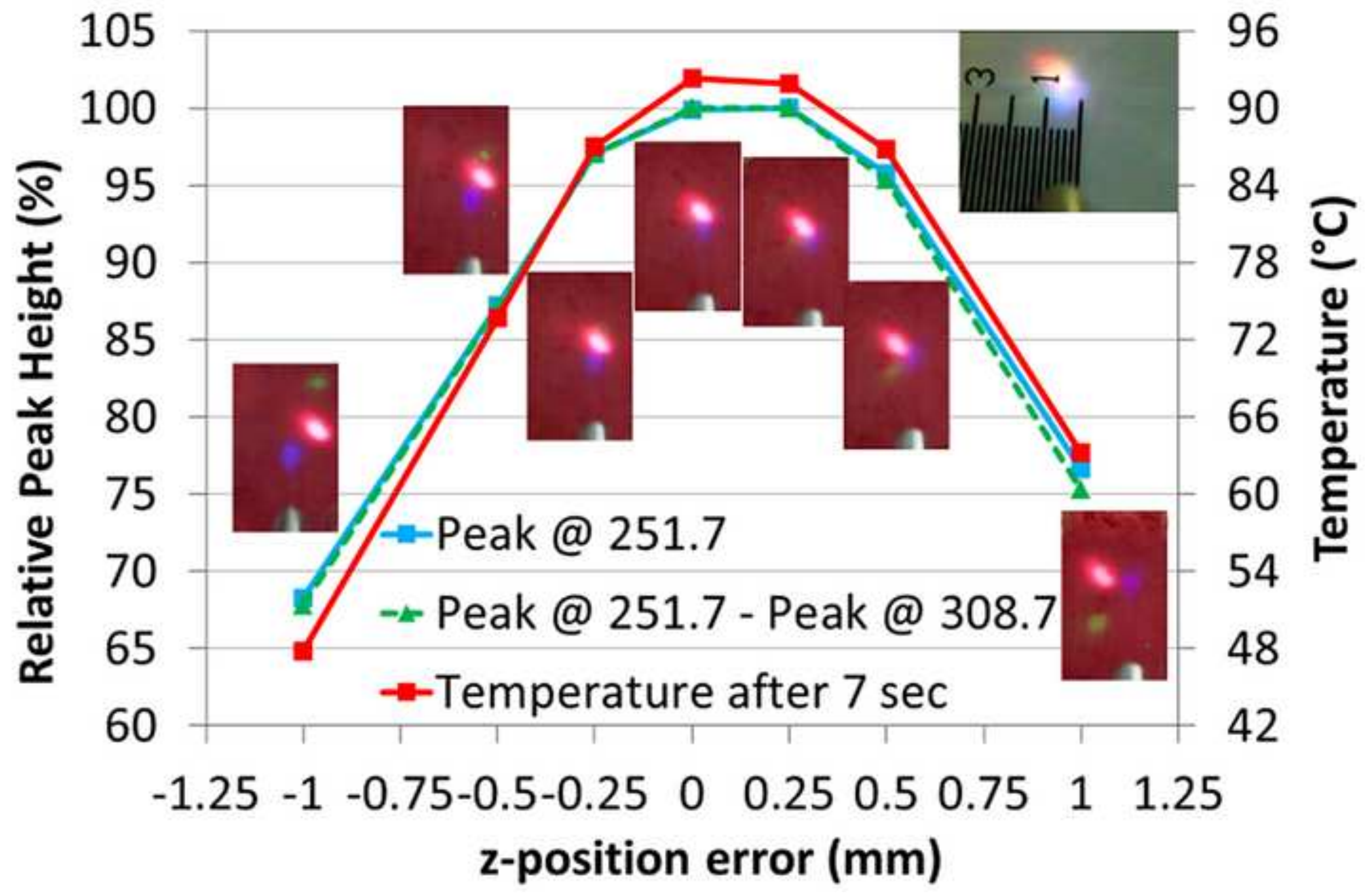




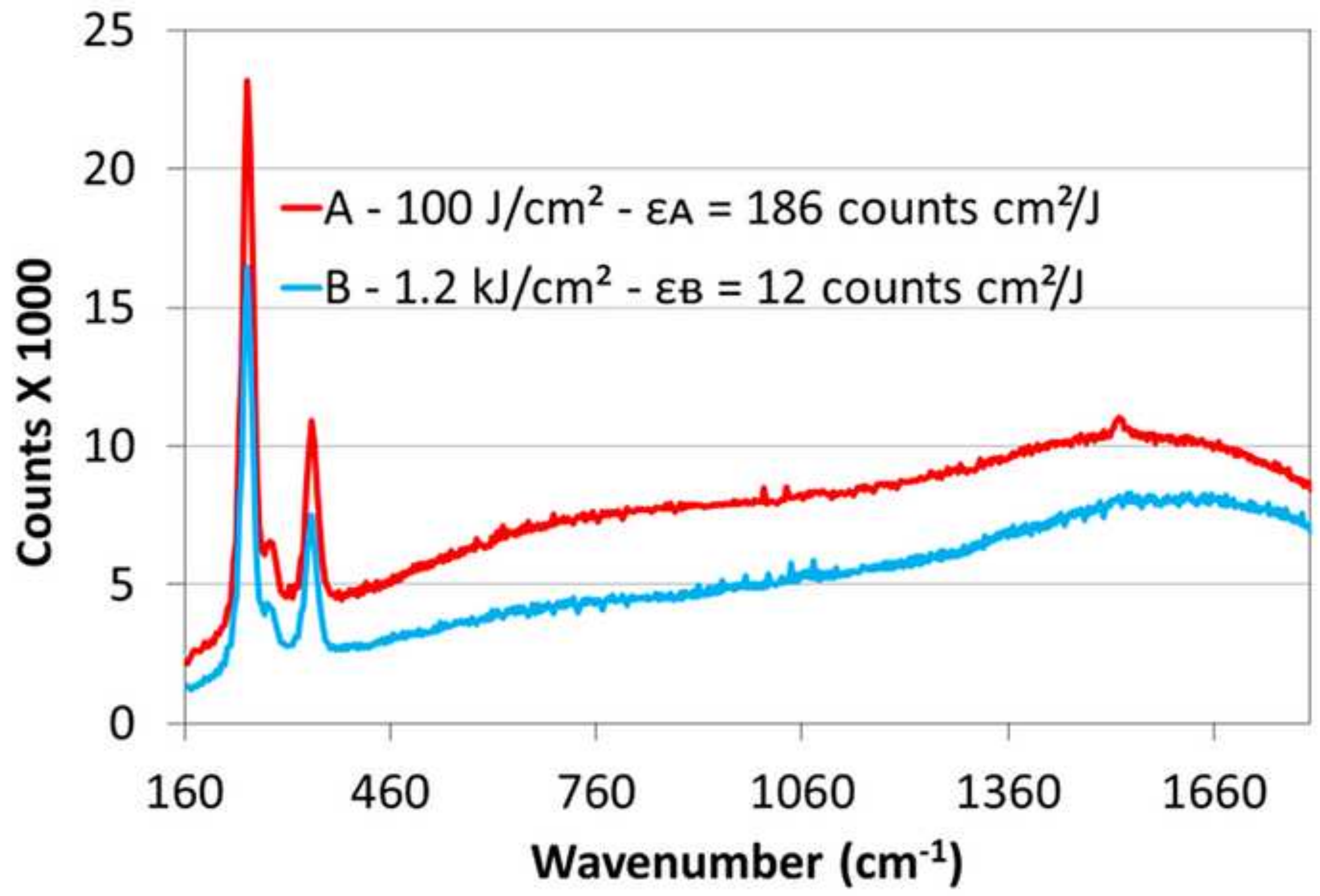




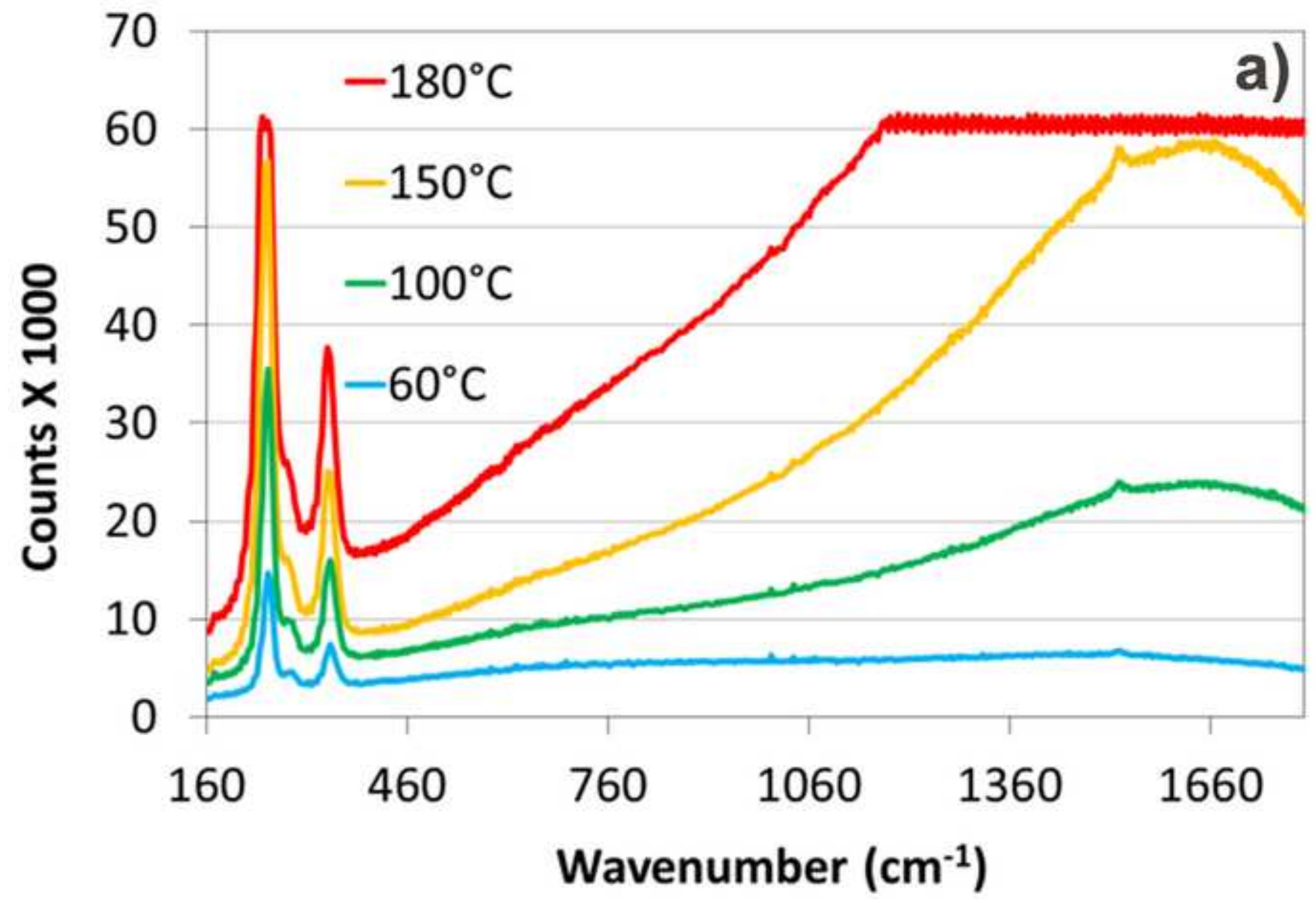




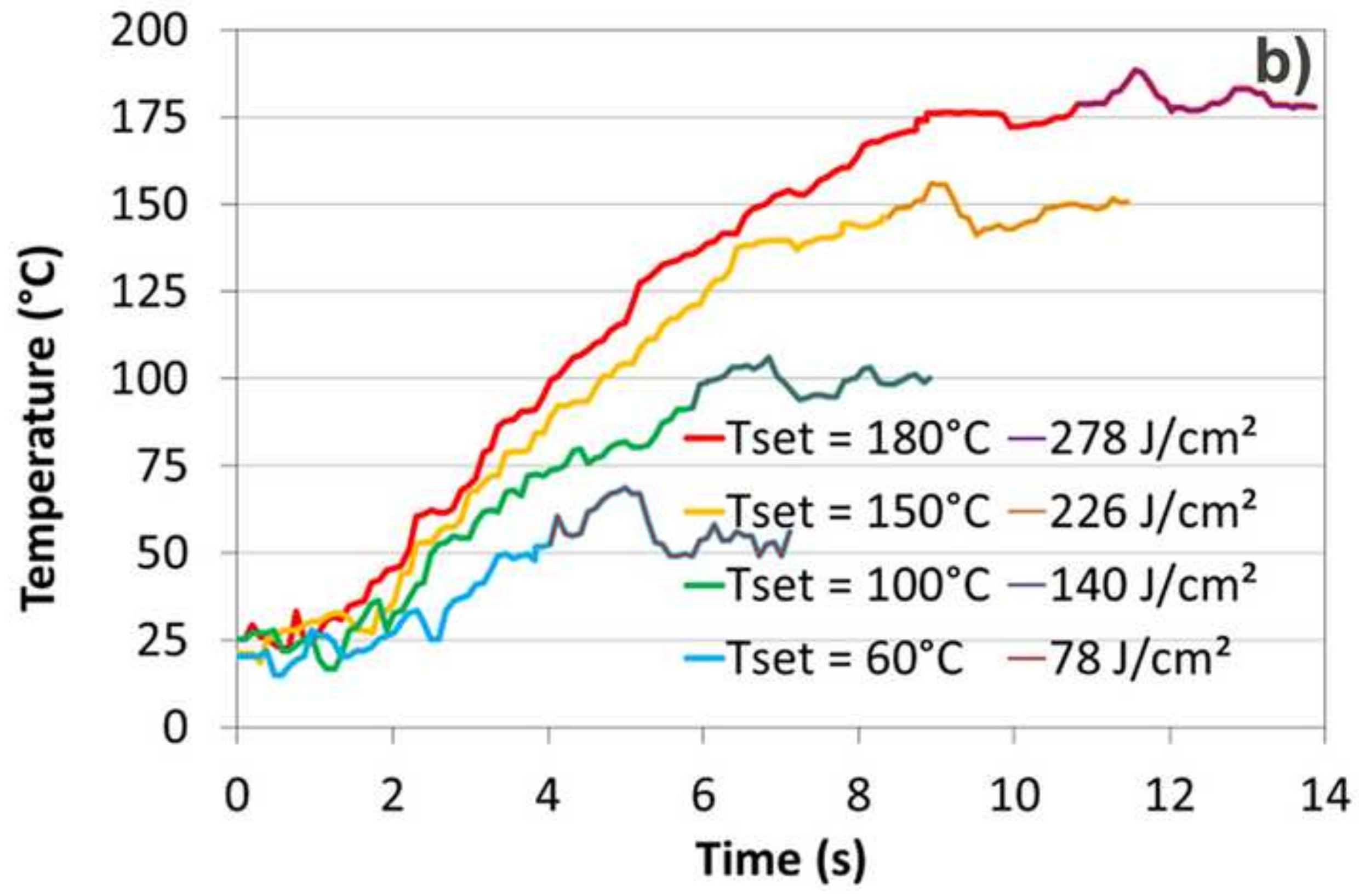




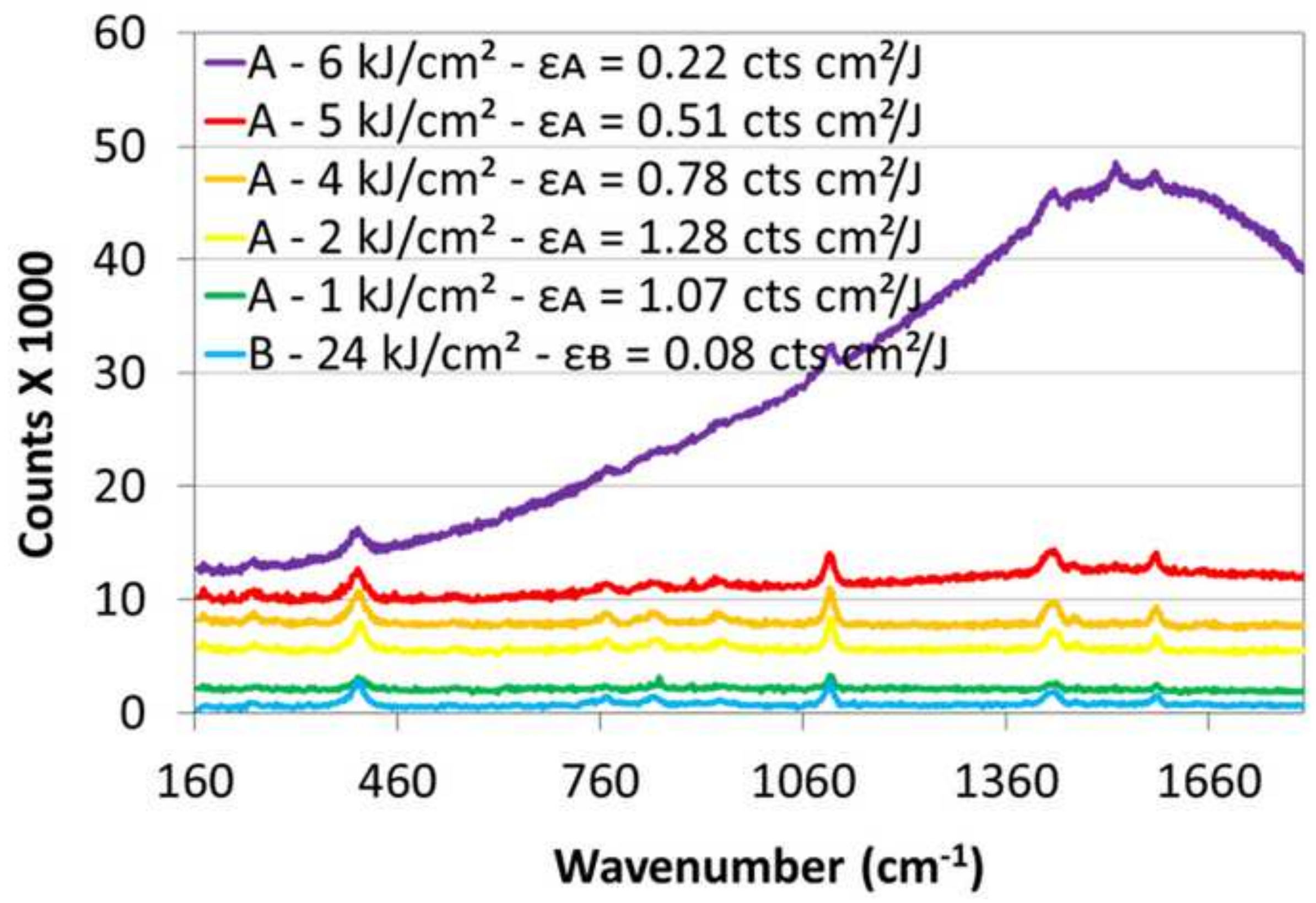




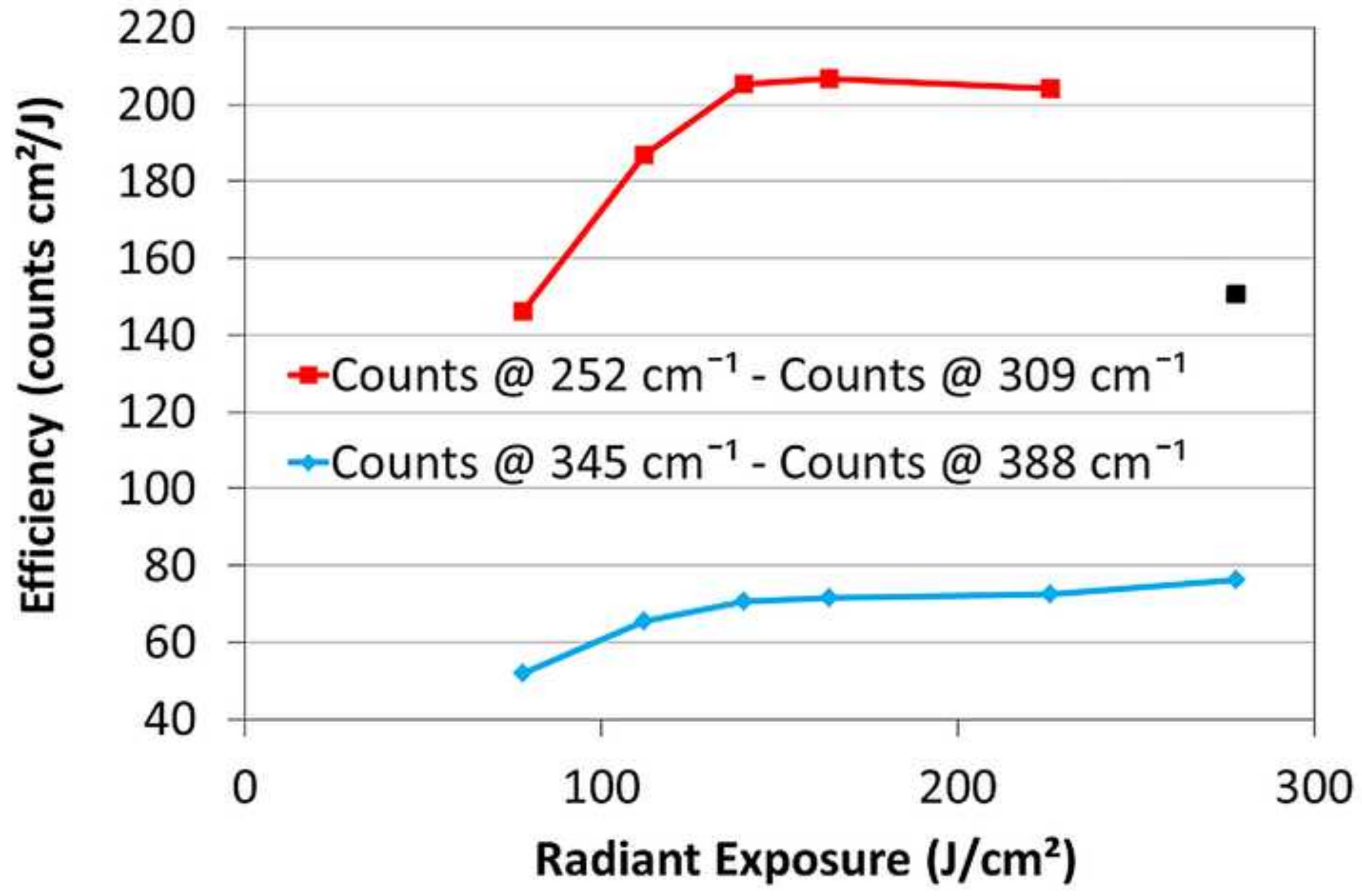




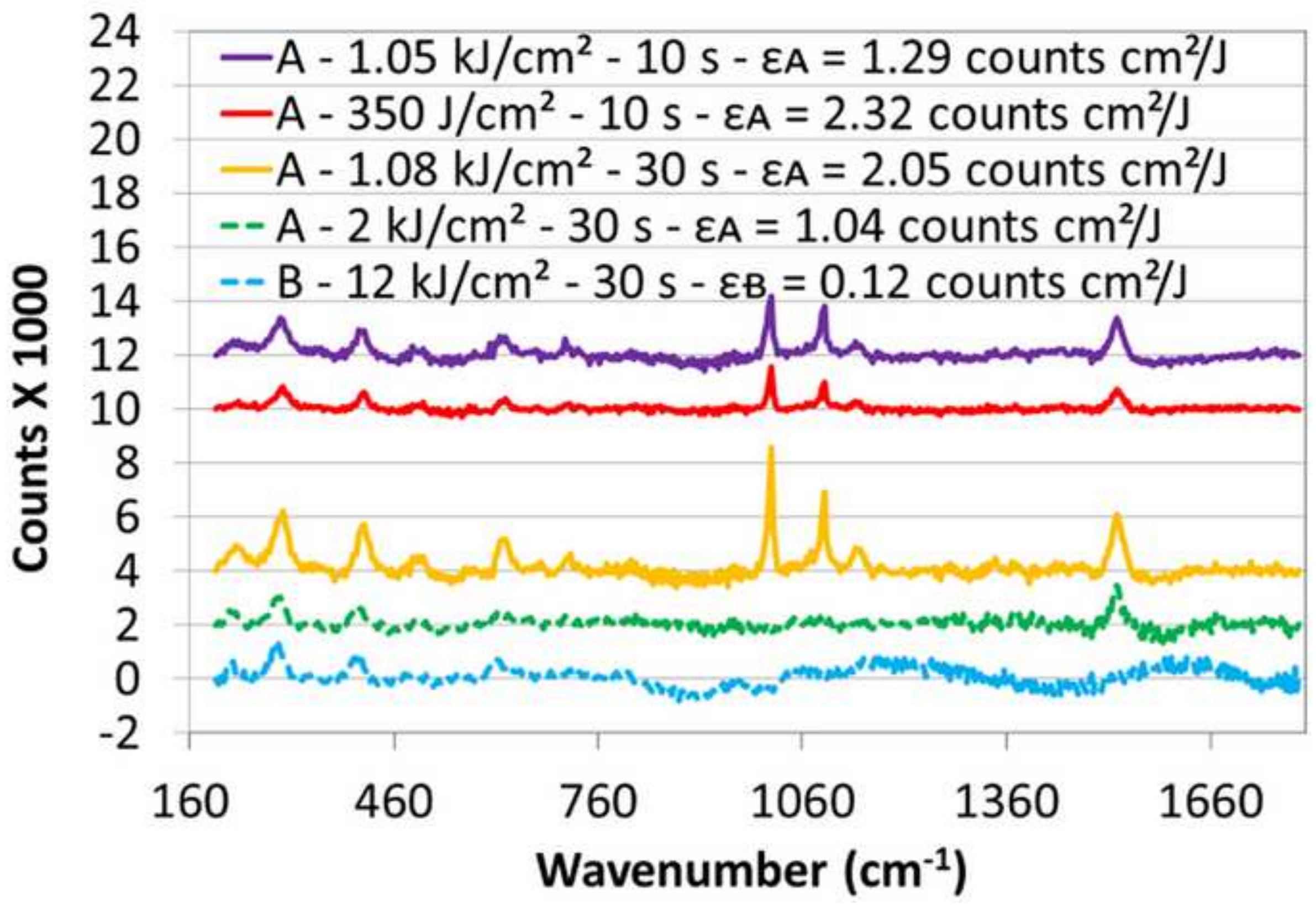




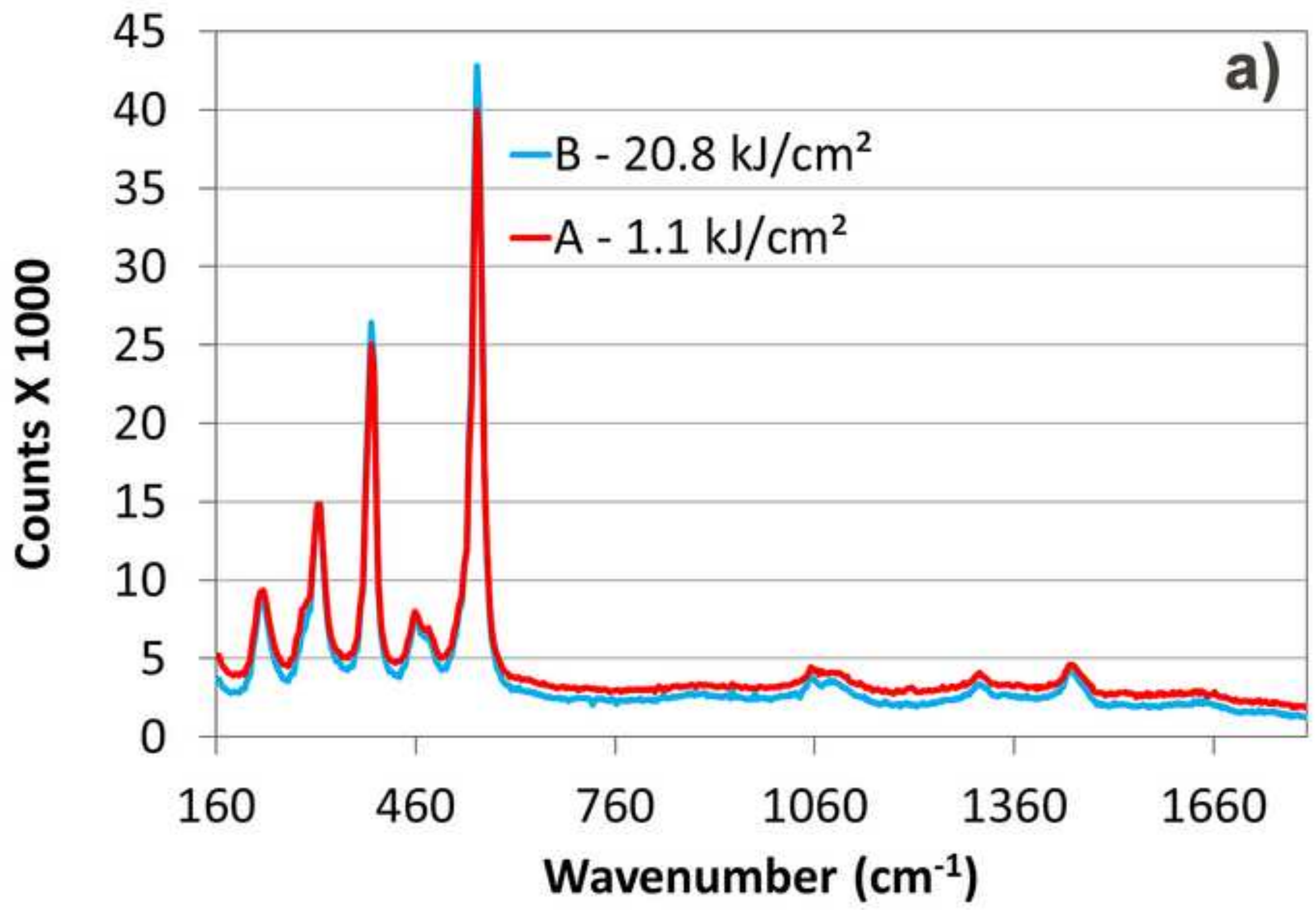




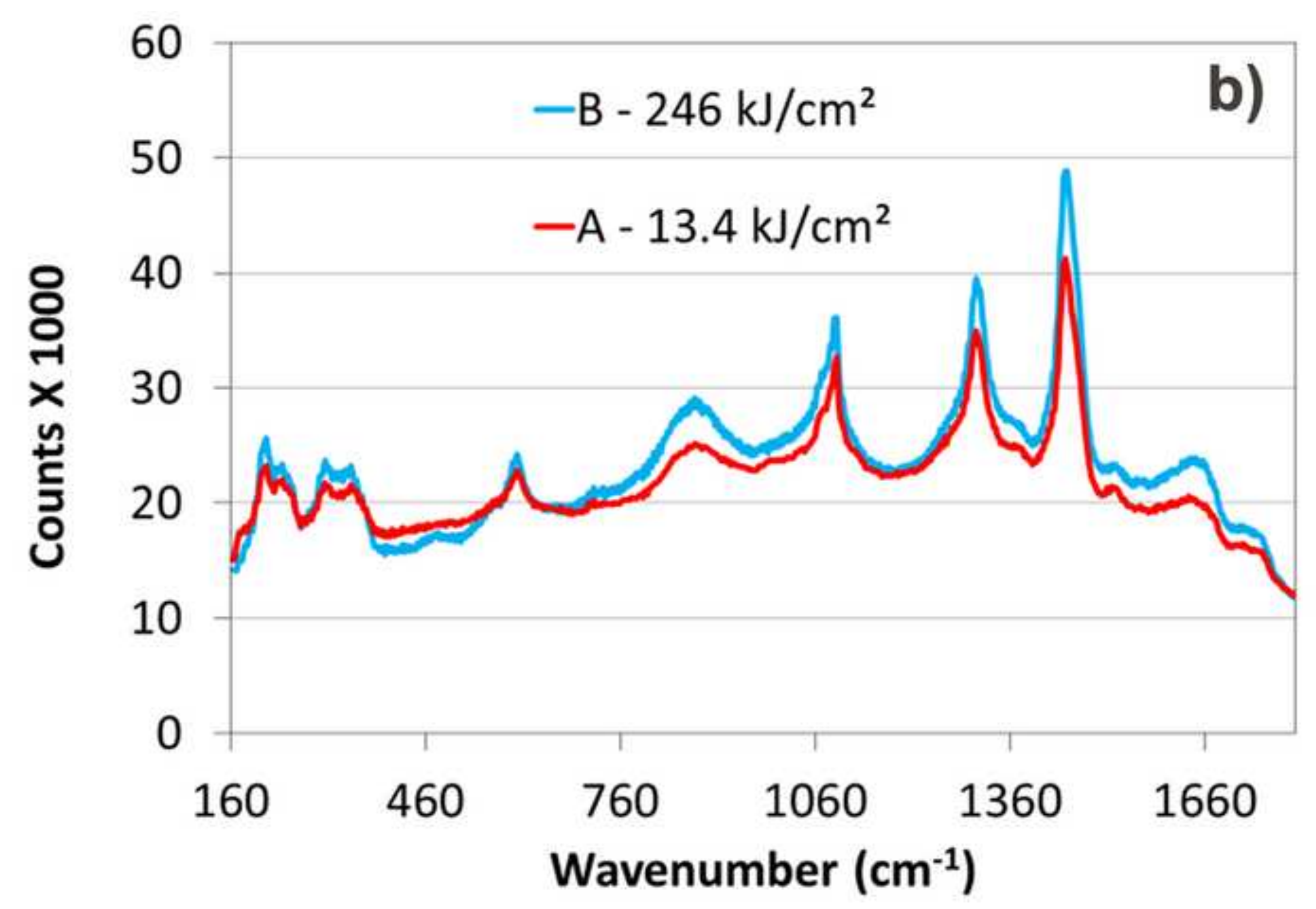

Fig. $11 \mathrm{~b} . .$. and cadmium yellow (b) oil paint ... 